\title{
Effect of Occupational and Recreational Activity on the Risk of Colorectal Cancer among Males: A Case-Control Study
}

\author{
STEVEN MARKOWITZ, * ALFREDO MORABIA, ${ }^{\dagger}{ }^{\ddagger}$ KAREN GARIBALDI* AND ERNST WYNDER, ${ }^{\dagger}$
}

\begin{abstract}
Markowitz S (Division of Environmental and Occupational Medicine, Department of Community Medicine, Box 1057 , Mount Sinai School of Medicine, 1 Gustave Levy Place, New York, NY 10029, USA), Morabia A, Garibaldi K and Wynder E. Effect of occupational and recreational activity on the risk of colorectal cancer among males: Results of a case-control study. Internationa/ Journa/ of Epidemiology 1992; 21: 1057-1062.

Epidemiological studies have consistently demonstrated that either occupational or recreational physical activity is protective against colon cancer. However, it is unclear whether recreational activity is similarly protective among those who engage in high or low occupational activity. We therefore compared 440 male cases of colorectal cancer with 1164 male hospital patients. Occupational activity was defined according to job title, while recreational activity was assessed by questionnaire for three different periods of life. Occupational activity was protective with respect to colorectal cancer irrespective of whether one engaged in recreational activity at any different period of life. In contrast, recreational activity, performed at $20-44$ years of age appeared to decrease colon cancer risk by $10-25 \%$ irrespective of the intensity of job activity. The present results suggest that, although we observed a larger effect with occupational activity than with recreational activity, middle-aged men may reduce their risk of colorectal cancer if they exercise when they are not working. These findings need to be confirmed in other populations.
\end{abstract}

Since the original observations by Garabrant $e t$ al. in $1984^{1}$ and Vena et al. in $1985,{ }^{2}$ epidemiological studies have consistently demonstrated that increased physical activity is associated with a reduced risk of colon cancer. The protection conferred by physical activity has been observed in a variety of nationalities and ethnic groups, including continental North Americans on the East and West coasts, Japanese men residing in Hawaii, Swedes, mainland Chinese, and Chinese-Americans. ${ }^{1-12}$ In the past 8 years, six casecontrol studies ${ }^{2,7-10,12}$ and six cohort studies ${ }^{1,3-6,11}$ have shown a $20-40 \%$ reduction in colon cancer among those with high physical activity relative to low activity. This reduction in risk has been found among men, ${ }^{1-10}$ women, ${ }^{4,7,10}$ younger (25-44 years) $)^{8}$ and older age groups $\left(\geqslant 65\right.$ years). ${ }^{2}$

While such a reduction in risk appears modest, the high incidence of colon cancer in Western Europe and

\footnotetext{
- Division of Environmental and Occupational Medicine, Department of Community Medicine, Box 1057, Mount Sinai School of Medicine, 1 Gustave Levy Place, New York, NY 10029, USA.

$\dagger$ Clinical Epidemiology Unit, University Canton Hospital, Geneva, Switzerland.

I American Health Foundation, 320 E 43 St, New York, NY, USA.
}

North America enhances the importance of these findings. Approximately 157000 new cases of colon cancer were expected to occur among both sexes in the US in $1991^{13}$ and, therefore, even a $20 \%$ reduction in risk of colon cancer would mean 31000 fewer cancers each year.

Published studies of colon cancer have, until now, focused on either physical activity intrinsic to occupation, recreational, or total activity. ${ }^{1-12,14,15}$ To our knowledge, only one study has examined the joint effect of recreational and occupational activity. ${ }^{10}$ We therefore conducted the present study to evaluate whether recreational activity has a protective effect independent of occupational activity and to determine the importance of recreational activity at different ages with respect to subsequent risk of colorectal cancer.

\section{METHODS}

Between 1985 and 1990, 443 male patients with the diagnosis of colon (ICD-9 code: 153 ) or rectosigmoid (ICD-9 code: 154) cancer were identified in nine hospitals in the following cities or geographical areas in the US: New York, Long Island, Detroit, Chicago, 
Philadelphia and Pittsburgh. All cases were confirmed histologically. The analyses were not performed for females, because, using Garabrant's classification scheme, ${ }^{1}$ no females could be categorized as having high occupational activity. These patients were selected as part of a larger ongoing hospital-based case-control study, undertaken by the American Health Foundation since 1969 in order to identify risk factors for tobacco-related cancers.

The design of this study has been described elsewhere. ${ }^{16}$ Briefly, an attempt is made to interview all newly diagnosed cases with tobacco-related cancers (lung, upper respiratory and digestive tracts, pancreas, kidney and bladder) admitted to the participating hospitals. For each case, one control patient of the same age, race, sex, hospital and date of admission but suffering from a non-tobacco related disease is interviewed. Cases and controls of the present study are sampled from the control group of the American Health Foundation study. We did not include patients accrued before 1985, because histological types of colon cancers prior to 1985 were not available, and information on occupation and on recreational activity was less extensive. Tobacco-related diagnoses are excluded, because smoking is correlated with other health-related behaviours, in particular physical activity. ${ }^{17,18}$

Cases were all patients with colorectal cancer ( $n=443)$, including caecum $(n=16)$, ascending $(n=12)$, transverse $(n=17)$, descending $(n=6)$, sigmoid $(n=144)$, rectum $(n=135)$, and other colon $(n=113)$. For each of these cases, we selected all available controls, including a minimum of one and a maximum of four, from the pool of cancer and noncancer patients interviewed between 1985 and 1990 who were free of tobacco-related diseases or of leukaemia. Controls were matched to each colorectal case on age ( \pm 5 years), sex, race, hospital, and date of admission ( \pm 2 years). Diagnoses among the 1164 controls included cancers $(721$, or $62 \%$ ) of the stomach $(19 \%)$, prostate $(18 \%)$, skin $(18 \%)$, sarcoma $(16 \%)$, myeloma and lymphoma (12\%) and other sites $(17 \%)$. Non-cancer controls ( 443 or $38 \%$ ) had benign tumours $(14 \%)$, fractures, traumas and vertebral disc problems $(12 \%)$, arthritis $(7 \%)$, non-infectious kidney diseases $(7 \%)$ and other non-neoplastic diseases $(60 \%)$.

Information on sociodemographic and anthropometric characteristics, and recreational activity was obtained from the study participants through a structured standardized questionnaire administered by trained interviewers. Quetelet's index was based on the patient's weight 5 years prior to diagnosis. Respondents were also asked whether they had engaged in 26 different types of regular recreational physical activity (e.g. tennis, basketball etc.) during three specific periods of life (15-21 years, 22-44 years and $\geqslant 45$ years). Recreational activity was defined as 'exercise carried out for at least 20 minutes, three times a week, for 1 year or more'. In the present analysis, the indicator of recreational activity was whether or not the subject had engaged in any recreational activity during the three age periods specified above. Additional details regarding the measurement of recreational activity in the ongoing case-control study of the American Health Foundation are described elsewhere. ${ }^{19}$

Occupational activity level was defined as usual occupation classified into high, moderate and low activity levels according to Garabrant's scheme.' Garabrant $e t$ al . assigned an occupation a high activity rating if it involved physical activity more than $80 \%$ of the time, a moderate activity rating if the job required physical activity $20-80 \%$ of the time, and a low activity rating if physical activity was required less than $20 \%$ of the time. ${ }^{1}$ Information on occupation and attendant activity level was missing for three cases and eight controls.

We estimated the relative risk of colorectal cancer by the odds ratios (OR). Because the number of cases with high activity level was small, we used low activity as the reference category and, therefore, estimated the relative protective effect of engaging in physical activity.

Unconditional logistic regression was used to compute OR. Because controls were individually matched to cases, we adjusted for some of the matching factors, i.e. age (six categories), geographical area (New York, Long Island, Detroit and Chicago, Pittsburgh and Philadelphia) and race. In the presence of individual matching, unconditional logistic regression with adjustment for the matching factors yields OR equivalent to those that would have been obtained using conditional logistic regression. ${ }^{20}$ In addition, the OR have smaller variance, and the technique gives more flexibility to explore interactions between risk factors. Trends in the OR as well as potential interactions between recreational and job activity were also assessed using logistic regression. Departure from the logistic regression model assumption was checked by examination of the differences between observed and expected numbers of cases in each stratum for which OR was computed. ${ }^{20}$

\section{RESULTS}

There were no case-control differences in the distribution of age, marital status, education, religion, or 
Quetelet's index (not shown in Table). Table 1 shows that a majority of the subjects, but more cases than controls, were white collar workers.

TABLE 1 Distribution of accupations among the cases and controls

\begin{tabular}{lrrrr}
\hline & Cases & (4) & Controls & $(\mathbf{4})$ \\
\hline Occupation & 79 & $(17.9)$ & 199 & $(17.1)$ \\
Managers & 133 & $(30.1)$ & 328 & $(28.2)$ \\
Professionals and technicians & 41 & $(9.3)$ & 87 & $(7.5)$ \\
Sales & & & & \\
Administrative support and & 23 & $(5.2)$ & 69 & $(5.9)$ \\
$\quad$ clerical & 5 & $(1.1)$ & 27 & $(2.3)$ \\
Service & 0 & $(0)$ & 9 & $(0.8)$ \\
Farming, forestry and fishing & 113 & $(25.6)$ & 311 & $(26.8)$ \\
Skilled crafts and repair workers & 26 & $(5.9)$ & 59 & $(5.1)$ \\
Operatives, assemblers, inspectors & 16 & $(3.6)$ & 50 & $(4.3)$ \\
Transportation & 6 & $(1.4)$ & 23 & $(2.0)$ \\
Labourers & 2 & $(0.3)$ & 2 & $(0.1)$ \\
Missing data & & & & \\
& 444 & 100 & 1164 & 100 \\
Total & & & & \\
\hline
\end{tabular}

As shown in Table 2, the risk of cancer of the colon and rectum decreased as the occupational activity increased. For colon cancer, the OR was 0.5 for both moderate activity and high activity occupations, relative to sedentary jobs. The trend in risk of rectal cancer was similar in direction and magnitude for high activity occupations, though only the OR for colon cancer reached statistical significance.

Table 3 presents the results combining the cancer sites. The adjusted $\mathrm{OR}$ for moderate activity jobs was $0.8(95 \%$ confidence interval $[\mathrm{CI}]: 0.6-1.0)$, and the adjusted OR for high activity jobs was $0.5(95 \% \mathrm{CI}$ : $0.3-0.8)$ using the low activity as a reference group ( $P$ for trend $=0.006$ ). Table 3 also shows that this effect
TABLE 2 Assaciation of accupational activity and colorectal cancer by cancer site, in US male hospital patients, $1985-1990$

Site

\begin{tabular}{|c|c|c|c|c|c|c|}
\hline \multirow[b]{2}{*}{$\begin{array}{l}\text { Occupational } \\
\text { activity } \\
\text { levet }^{\mathrm{a}}\end{array}$} & \multicolumn{3}{|c|}{ Colon } & \multicolumn{3}{|c|}{ Rectum } \\
\hline & $\begin{array}{c}\text { Cases } \\
\text { No. }\end{array}$ & $O R^{b}$ & (95\% CI) & $\begin{array}{c}\text { Cases } \\
\text { No. }\end{array}$ & $\mathrm{OR}^{\mathrm{b}}$ & $(95 \% \mathrm{CI})$ \\
\hline Low & 59 & 1.0 & (reference) & 34 & 1.0 & (reference) \\
\hline Moderate & 231 & 0.5 & $(0.3-0.9)$ & 87 & 0.9 & $(0.5-1.7)$ \\
\hline High & 17 & 0.5 & $(0.3-0.8)$ & 12 & 0.6 & $(0.3-1.1)$ \\
\hline
\end{tabular}

OR = Odds Ratios.

- Using classification scheme of Garabrant. ${ }^{1}$

${ }^{b}$ Simultaneously adjusted for age, race, geographical area and recreatonal activity at age $22-44$ years.

was present when either cancer or non-cancer patients were used as controls; these controls are pooled in the other tables.

Table 4 provides $\mathrm{OR}$ and $95 \% \mathrm{CI}$ for colorectal cancer by level of job activity and recreational activity during different age periods. Increased job activity is protective against colorectal cancer regardless of the degree of recreational activity. The highest risk of disease is associated with those who have low occupational activity jobs, regardless of whether they engage in recreational activity. Although the number of subjects who exercised and who had highly active jobs is small, they have the lowest risk of colorectal cancer (OR $=0.3,0.4,0.6$ for the three age periods). Job activity results in a more consistent and stronger effect on risk of colorectal cancer than does leisure time activity.

TABLE 3 Odds ratios (OR) for colorectal cancer, by occupational activity level among US male haspital patients, $1985-1990$

\begin{tabular}{|c|c|c|c|c|c|c|}
\hline \multirow[b]{2}{*}{$\begin{array}{l}\text { Occupational } \\
\text { activity } \\
\text { lever }\end{array}$} & \multirow[b]{2}{*}{$\begin{array}{c}\text { Cases } \\
\text { No. }\end{array}$} & \multirow[b]{2}{*}{$\begin{array}{c}\text { Cancet } \\
\text { controls } \\
\text { No. }\end{array}$} & \multirow[b]{2}{*}{$\begin{array}{l}\text { Non-cancer } \\
\text { controls } \\
\text { No. }\end{array}$} & \multicolumn{3}{|c|}{ OR $(95 \% \mathrm{CI})$} \\
\hline & & & & $\begin{array}{c}\text { Crude } \\
\text { Cancet } \\
\text { controls }\end{array}$ & $\begin{array}{l}\text { Crude } \\
\text { Non-cancer } \\
\text { controls }\end{array}$ & $\begin{array}{l}\text { Adjusted }^{b} \\
\text { Overall }\end{array}$ \\
\hline Low & 93 & 127 & 71 & 1.0 & 1.0 & 1.0 (reference) \\
\hline Moderate & 318 & 527 & 308 & 0.8 & 0.8 & $0.8(0.6-1.0)$ \\
\hline High & 29 & 64 & 59 & 0.6 & 0.4 & $0.5(0.3-0.8)$ \\
\hline \multicolumn{3}{|c|}{ Trend $\chi^{2} 1 \mathrm{df}$ ( $P$-value) } & & $3.5(0.07)$ & $10.9(0.001)$ & $7.5(0.006)$ \\
\hline
\end{tabular}

'According to Garabrant classification scheme'.

${ }^{b}$ Simultaneously adjusted for age, race, geographical area and recreational activity at age 22-44 years. 
TABLE 4 Odds ratios (OR) of colorectal cancer according to accupational activity and of recreational activity at three different age-periods of male haspital patients, $1985-1990$

\begin{tabular}{|c|c|c|c|c|c|c|c|c|c|c|c|c|c|}
\hline \multirow[b]{3}{*}{ Age period } & \multirow{3}{*}{$\begin{array}{l}\text { Recreational } \\
\text { activity }\end{array}$} & \multicolumn{9}{|c|}{ Occupational activity** } & \multirow{2}{*}{\multicolumn{3}{|c|}{ All }} \\
\hline & & \multicolumn{3}{|c|}{ Low } & \multicolumn{3}{|c|}{ Moderate } & \multicolumn{3}{|c|}{ High } & & & \\
\hline & & Cases & $\mathrm{OR}^{\mathrm{a}}$ & $(95 \% \mathrm{Cl})$ & Cases & $\mathrm{OR}^{a}$ & $(95 \% \mathrm{CI})$ & Cases & $\mathrm{OR}^{\mathbf{b}}$ & $(95 \% 5 \mathrm{Cl})$ & Cases & $O R^{c}$ & (95\% Cl) \\
\hline \multirow[t]{2}{*}{$15-21$ years } & No & 43 & 1.0 & (reference) & 175 & 0.8 & $(0.5-1.2)$ & 22 & 0.7 & $(0.4-1.3)$ & 240 & 1.0 & (reference) \\
\hline & Yes & so & 1.0 & $(0.6-1.7)$ & 143 & 0.8 & $(0.5-1.3)$ & 7 & 0.3 & $(0.1-1.3)$ & 200 & 1.0 & $(0.8-1.2)$ \\
\hline \multirow[t]{2}{*}{$22-44$ years } & No & 65 & 1.0 & (reference) & 251 & 0.8 & $(0.6-1.2)$ & 26 & 0.5 & $(0.3-0.9)$ & 342 & 1.0 & (reference) \\
\hline & Yes & 28 & 0.9 & $(0.5-1.5)$ & 67 & 0.6 & $(0.3-0.9)$ & 3 & 0.4 & $(0.1-1.3)$ & 98 & 0.7 & $(0.5-0.9)$ \\
\hline \multirow[t]{2}{*}{$>45$ years } & No & 60 & 1.0 & (reference) & 225 & 0.9 & $(0.6-1.3)$ & 22 & 0.6 & $(0.3-1.0)$ & 307 & 1.0 & (reference) \\
\hline & Yes & 27 & 1.1 & $(0.6-1.9)$ & 81 & 0.7 & $(0.5-1.1)$ & 5 & 0.6 & $(0.3-0.9)$ & 113 & 0.9 & $(0.7-1.1)$ \\
\hline
\end{tabular}

a Simultaneously adjusted for age, race and geographical area.

b According to Garabrant classification.'

c Also adjusted for occupational activity level.

The protective effect of engaging in recreational activity is strongest in the group that exercised at age 22-44 years of age (Table 4). In addition, during this age period, recreational activity results in a $10 \%$ $(0.9 / 1.0)$ to $25 \%(0.4 / 0.5)$ reduction in risk of colorectal cancer regardless of the degree of occupational activity. This suggests that the two types of activities have independent effects on the relative risk of colorectal cancer.

\section{DISCUSSION}

This study confirms and extends highly consistent prior observations that physical activity decreases the risk of colon cancer. In most reports, this protective effect is attributed to either increased peristaltic activity of the colon ${ }^{21}$ or to increased prostaglandin secretion. 22,23 We also found an association of physical activity with a reduction in risk of cancer of the rectum, as has been observed in some studies, ${ }^{10,14}$ though not as consistently as with cancer of the colon. In our study, the OR for rectal cancer and different levels of activity did not attain statistical signficance, probably because the number of cases of rectal cancer is limited (but the trend is clear).

In the present study, occupational activity is more strongly related to colon cancer than recreational activity, a finding consistent with the fact that for males, most physical activity occurs at work. While the general protective trend of occupational and recreational activity was seen at all ages of participation in recreational activity, the effect was strongest among those who reported increased exercise at age 22-44. One explanation is that most males engage in some physical activity at college, but only those who are truly active persist in exercising in their 20 s and 30 s. Indeed, $45 \%$ of the respondents reported that they exercised at age $15-21$ versus only $22 \%$ at age $22-44$ (Table 4). Another explanation is that the protective effect of physical activity is operative relatively early in the sequence of steps in the development of cancer of the colon and rectum, but not after age 45 , even though exercising may be beneficial in terms of other diseases.

Few previous studies have examined the separate effects of occupational and recreational activity on the risk of colon and/or rectal cancer. Severson et al. ${ }^{6}$ noted a $30 \%$ reduction in risk of colon cancer among individuals who reported moderate or heavy activity at work and a similar reduction in risk among those who reported moderate or heavy recreational activity. In a study comparing the risk of colorectal cancer among mainland Chinese and Chinese-Americans, Whittemore et al..$^{10}$ examined both occupational and non-occupational activity using Garabrant's job activity rating system and a semiquantitative approach to calorie consumption in non-occupational activity. The effect of each type of activity was evaluated separately. Among Chinese-American men, both high recreational and high occupational activity were associated with a decreased risk of colon and rectal cancer. Job activity had a greater protective effect against colon cancer. Albanes et al. ${ }^{12}$ used NHANES I data to assess the effect of self-reported non-recreational (including occupational) and recreational activity on colon cancer risk. Although their measure of occupational activity was crude, they found that only non-recreational 
activity was associated with a decreased risk of colon cancer.

That different levels of physical activity at different ages may have a variable impact on the subsequent development of colorectal cancer has also been little studied and remains controversial. Paffenbarger et al. " examined the importance of participation in college sports to subsequent risk of cancer of the colon and other organs and found a reduced risk of rectal cancer but not colon cancer among those reporting 5 or more hours per week of college sports activity. In a second long-term study of male Harvard alumni, Paffenbarger et al.$^{11}$ related self-reported descriptions of recreational activity converted to weekly kilocalorie consumption in the early and mid-1960s to subsequent development of colon cancer (and other cancers) during the next 12-16 years. They found no decrease in risk of colon and rectal cancer among those who exercised. In contrast, Whittemore's case-control study of colon cancer among Chinese in North America and China, ${ }^{10}$ showed a protective effect was found for physical activity assessed either during the year prior to diagnosis or 20 years before.

In the present study, occupational activity level was based on the usual occupation, and recreational activity was self-reported. These measures of physical activity are not more refined than those in previous reports. However, it is reassuring that different indicators of physical activity were found by Slattery $e t$ $a l .{ }^{14}$ to be consistently associated with a decreased risk of colon cancer. The possibility of recall bias in the self-reporting of recreational activity one to five decades prior to interview must be acknowledged ${ }^{18}$ but seems unlikely since similar associations were obtained using either cancer or non-cancer controls.

Although we did not attempt to remove a potential confounding effect of alcohol, caloric intake, fibre or saturated fat, these dietary factors have been usually shown to be independent risk factors for colorectal cancer. ${ }^{5,7,10}$ In addition, it is important to note that if total caloric intake, fat, or fibre were confounders, our results would underestimate the true relative risk since subjects at higher risk due to low physical activity tend to have a lower consumption of fat, fibre, and total calories compared to subjects with highly active jobs. ${ }^{7}$

The exclusion of tobacco-related diagnoses from the control group may have introduced some bias. However, since colorectal cancer is not caused by cigarette smoking, inclusion of tobacco-related diagnoses among the controls would have led to a higher rate of cigarette smokers among the controls than among the cases. Since cigarette smoking is negatively correlated with physical activity, ${ }^{17,18}$ including patients with tobacco-related diseases as controls would have artificially reduced the physical activity levels of the control group and led to a biased overestimation of the relative risk.

While it would have been interesting to analyse the impact of physical activity on colorectal cancer by subsite of cancer within the colon, too few cases ( 17 cases or less) were available for any specific colon subsite other than the sigmoid region to permit such an analysis.

Our findings and those of previous studies ${ }^{1-12}$ have an important implication for the evaluation of the effect of asbestos on the risk of colorectal cancer. Occupational exposure to asbestos is most likely to occur in occupations or industries that also require a moderate or high level of physical activity, i.e. manufacturing and construction. Physical activity may therefore be an important cofactor in the relationship between asbestos and the incidence of colorectal cancer. Indeed, two studies have evaluated colorectal cancer mortality among asbestos-exposed workers compared to two types of controls: a) blue collar workers not exposed to asbestos, and b) general male population. 24,25 In Seidman's study of 943 asbestos factory workers in Paterson, New Jersey, the relative risk of death from colorectal cancer was 2.1 when the study group was compared to the mortality rate of the New Jersey male population and 3.0 when compared to mortality rate of blue collar controls. ${ }^{24}$ Similarly, Selikoff found a mortality ratio of 1.6 for colorectal cancer among 17800 North American insulators when compared to the mortality rate of US white males, which increased to 1.8 when compared with the mortality rate among blue collar controls. ${ }^{25}$ Most other studies of the relationship between asbestos exposure and colorectal cancer use general population mortality data for comparison and, therefore, may underestimate the true risk of colorectal cancer caused by asbestos exposure.

In conclusion, our results suggest that risk of colorectal cancer is independently decreased by occupational and recreational activity, especially if the latter occurs at age $22-44$ years. This finding has important public health implications, since it suggests that middle-aged men with moderate or high occupational activity will equally benefit from recreational exercise in terms of reduction in risk of colorectal cancer. However, since the only other study that reports the joint effect of occupational and recreational activity found no effect from the latter, the present findings need to be replicated in other populations and with other study designs. 


\section{ACKNOWLEDGEMENTS}

We thank Katherine Gleaton for secretarial assistance and are grateful to Dr David Garabrant for providing us with his classification of jobs according to physical activity. We also thank Dr Geoffrey Kabat for his comments.

Supported in part by a Public Health Service grant through National Cancer Institute Center Grant CA-17613 and American Cancer Society Special Institutional Grant SIG-8.

\section{REFERENCES \\ ${ }^{1}$ Garabrant D H, Peters J M, Mack T M, Bernstein L. Job activity and colon cancer risk. Am J Epidemiol 1984; 119: 1005-14.}

2 Vena J E, Graham S, Zielezny M, Swanson M K, Barnes R E, Nolan J. Lifetime occupational exercise and colon cancer. Am $J$ Epidemıol 1985; 122: 357-65.

${ }^{3}$ Gerhardsson M, Norell S E, Kiviranta H, Pedersen N L, Ahlbom A. Sedentary jobs and colon cancer. Am J Epidemiol 1986; 123: $775-80$.

${ }^{4}$ Vena J E, Graham S, Zielezny M, Brasure J, Swanson M K. Occupational exercise and risk of cancer. Am J Clin Nutr 1987; 45: 318-27.

${ }^{5}$ Wu A H, Paganini-Hill A, Ross R K, Henderson B E. Alcohol, physical activity and other risk factors for colorectal cancer: A prospective study. Br J Cancer 1987; 55: 687-94.

${ }^{6}$ Severson R K, Nomura A A M, Grove J S, Stemmermann G N. A prospective analysis of physical activity and cancer. $A m \mathrm{~J}$ Epidemiol 1989; 130: 522-29.

${ }^{7}$ Slattery M L, Schumacher MC, Smith K R, West DW, Abd-Elgany N. Physical activity, diet, and risk of colon cancer in Utah. Am J Epıdemiol 1988; 28: 989-99.

${ }^{8}$ Peters R K, Garabrant D H, Yu M C, Mack T M. A case-control study of occupational and dietary factors in colorectal cancer in young men by subsite. Cancer Res 1989; 49: 5459-68.

${ }^{9}$ Brownson R C, Zahm S H, Chang J C, Blair A. Occupational risk of colon cancer. Am J Epidemiol 1989; 130: 675-87.

${ }^{10}$ Whittemore A S, Wu-Williams A H, Lee M, et al. Diet, physical activity and colorectal cancer among Chinese in North America and Chına. J Natl Cancer Inst 1990; 82: 915-26.

${ }^{11}$ Paffenbarger R S, Hyde R T, Wing A L. Physical activity and incidence of cancer in diverse populations: a preliminary report. Am J Clin Nutr 1987; 45: 312-17.
12 Albanes D, Blair A, Taylor P R. Physical activity and risk of cancer in the NHANES 1 population. Am J Public Health 1989; 79: 744-50.

${ }^{13}$ Boring C C, Squires T S, Tong T. Cancer Statistics, 1991. CA 1991; 41: $19-51$.

${ }^{14}$ Slattery M L, Abd-Elghany N, Kerber R, Schumacher M C. Physical activity and colon cancer: A comparison of various indicators of physical activity to evaluate the association. Epidemiology 1990; 481-85.

${ }^{15}$ Brownson R C, Chang J C, Davis J R, Smith C A. Physical activity on the job and cancer in Missouri. Am J Public Health 1991; 81: 639-42.

16 Wynder E L, Stellman S D. Comparative epidemiology of tobaccorelated cancers. Cancer Res 1977; 37: 4608-22.

${ }^{17}$ Schoenborn C A, Benson V. Relations between Smoking and Other Unhealthy Hobits: United States 1985. Advance Data from Vital and Health Statistics, No 154, DHHS Pub No (PHS) 88-1250. Hyattsville MD: Public Health Service, 1988.

18 Marks B L, Perkins K A, Metz K F, Epstein L H, Robertson R J, Goss $F \mathrm{~L}$, Sexton J E. Effect of smoking satus on content of caloric intake and energy expenditure. Int $J$ Eathrg Disorders 1991; 10: 441-49.

${ }^{19}$ Boffetta P, Barone J, Wynder E L. Leisure-time physical activity in a hospitalbased population. J Clin Epldemiolozy 1990; 43: 569-77.

${ }^{20}$ Brestow N E, Day N R, Halvorsen K T, Prentice R L, Sabai C. Extimation of multiple relative risk functions in matched casecontrol studies. Am J Epldemiol 1978; 108: 229-307.

${ }^{21}$ Holdstock D J, Misiewicz J J, Smith T, et al. Propulsion (mass movements) in the human colon and its relationship to meals and somatic activity. Gut 1970; 11: 91-99.

22 Demers L M, Harison T S, Halbert D R et al. Effect of prolonged exercise on plasma prostaglandin levels. Prastaglandins and Med 1981; 6: 413-18.

${ }^{23}$ Bartram H P, Wynder E L. Editorial. Physical Activity and Colon Cancer Risk? Physiological Considerations. Am J Gastroenterol 1989; 84: 109-12.

${ }^{24}$ Seidman H, Selikoff I J, Gelb S K. Mortality experience of amosite asbestos factory workers: Dose-response relationships 5 to $\mathbf{4 0}$ years after onset of short-term exposure. Am J Ind Med 1986; 10: 479-514.

${ }^{25}$ Selikoff I J, Hammond E C, Seidman H. Mortality experience of insulation workers in the United States and Canada, 1943-76. Ann NY Acad Sci 1979; 330: 91-116.

(Revised version received May 1992) 